\title{
The fasciated ear2 gene encodes a leucine-rich repeat receptor-like protein that regulates shoot meristem proliferation in maize
}

\author{
Fumio Taguchi-Shiobara, ${ }^{1}$ Zhuang Yuan, Sarah Hake, ${ }^{2}$ and David Jackson ${ }^{3}$ \\ Cold Spring Harbor Laboratory, Cold Spring Harbor, New York 11724, USA
}

\begin{abstract}
The ability to initiate organs throughout the lifecycle is a unique feature of plant development that is executed by groups of stem cells called meristems. The balance between stem cell proliferation and organ initiation is carefully regulated and ensures that organs can be initiated in regular geometric patterns. To understand how this regulation is achieved, we isolated a novel mutant of maize, fasciated ear2 (fea2), which causes a massive overproliferation of the ear inflorescence meristem and a more modest effect on floral meristem size and organ number. We cloned the fea2 gene using transposon tagging, and it encodes a membrane localized leucine-rich repeat receptor-like protein that is most closely related to CLAVATA2 from Arabidopsis. These findings provide evidence that the CLAVATA pathway for regulation of meristem size is functionally conserved throughout the angiosperms. A possible connection of fea2 to the control of crop yields is discussed.
\end{abstract}

[Key Words: Meristem; stem cells; fasciation; leucine-rich repeat; inflorescence; morphogenesis]

Received May 21, 2001; revised version accepted August 22, 2001.

Plant development is highly dynamic and involves the reiterative initiation of new primordia from groups of stem cells called meristems. Leaves and the axillary meristems that generate branches and flowers are initiated in regular patterns from the shoot apical meristem (SAM). SAMs have a remarkable ability to regulate their size during development, by exquisitely balancing cell proliferation with the incorporation of cells into new primordia (Sussex 1952; Medford 1992; Weigel and Clark 1996; Meyerowitz 1997). This balance is essential to maintain SAM integrity and the stereotypical pattern of organ initiation throughout development. Therefore, understanding the mechanisms regulating stem cell fate and proliferation is key to understanding SAM function and patterning of the shoot.

Genetic analysis of shoot meristem biology has progressed significantly in recent years (Evans and Barton 1997; Laufs et al. 1998b; Bowman and Eshed 2000). Mutants affecting meristem size can be grouped into two classes. The first class includes those affecting meristem formation and maintenance. For example, in strong alle-

Present addresses: ${ }^{1}$ Department of Biotechnology, National Institute of Agrobiological Resources, Tsukuba, Ibaraki 305-8602, Japan; ${ }^{2}$ USDA-UC Berkeley Plant Gene Expression Center, Albany, CA 94710, USA. ${ }^{3}$ Corresponding author.

E-MAIL jacksond@cshl.org; FAX (516) 367-8369.

Article and publication are at http://www.genesdev.org/cgi/doi/10.1101/ gad.208501 les of shootmeristemless (stm), seedlings arrest with no obvious shoot meristem after forming the cotyledons (Barton and Poethig 1993), though weak alleles indicate a role for STM throughout all stages of shoot development (Clark et al. 1996; Endrizzi et al. 1996). STM encodes a knotted1 (kn1)-related homeodomain protein, and consistent with their role in SAM initiation and maintenance, these genes are expressed throughout the SAM and down-regulated on the flanks where organs are initiated (Smith et al. 1992; Jackson et al. 1994; Long et al. 1996; Kerstetter et al. 1997; Vollbrecht et al. 2000). wuschel (wus) mutants are also impaired in stem cell maintenance (Laux et al. 1996). WUS encodes a homeodomain protein that is expressed before SAM initiation in the embryo, and becomes localized to a group of cells that underlies the presumptive stem cells, suggesting that it may signal stem cell fate nonautonomously (Mayer et al. 1998).

A second class of SAM mutants causes meristem enlargement, which in extreme cases can lead to fasciation. The term fasciation, from the Latin fascis, meaning bundle, describes variations in plant form resulting from proliferative growth. Fasciation was one of Mendel's 14 heritable characters in pea, and also has a long history of study in maize (Emerson 1912). Fasciated variants have significantly increased crop yields, for instance by increasing fruit size in tomato (Luckwill 1943; Zielinski 1945). 
Mutations in Arabidopsis that cause meristem enlargement include the clavata $(c l v)$ mutations (Leyser and Furner 1992; Clark et al. 1993, 1995; Kayes and Clark 1998), mgoun1 and mgoun2 (Laufs et al. 1998a), fasciata1 and fasciata2 (Leyser and Furner 1992; Kaya et al. 2001), and fully fasciated (Medford et al. 1992). clv mutants have larger shoot meristems and increased floral organ number, and strong alleles of clv1 and clv3 often fasciate (Clark et al. 1993, 1995). In contrast, clv2 mutants have relatively weak phenotypes, similar to weak clv1 or clv3 alleles; fasciation in clv2 mutants is observed only rarely, and only under short day growth conditions, possibly indicating genetic redundancy (Kayes and Clark 1998). clv3 mutants dominantly enhance $c l v 1$ (Clark et al. 1995), and clv2 mutants enhance weak or intermediate alleles of clv1 or clv3 (Kayes and Clark 1998), suggesting that these three genes act in the same pathway to regulate shoot meristem size. Insight into the molecular nature of this pathway has come from isolation of the $C L V$ genes; $C L V 1$ encodes a transmembrane leucine-rich repeat (LRR)-kinase, CLV2 encodes a protein with predicted transmembrane and LRR domains and only a very short intracellular region, and $C L V 3$ encodes a small protein that is predicted to be secreted (Clark et al. 1997; Fletcher et al. 1999; Jeong et al. 1999). Mosaic analysis of CLV3 supports the hypothesis that it encodes an intercellular signaling molecule (Fletcher et al. 1999). Biochemical studies have shown that CLV1 is present in two complexes; the smaller one consists of a disulfide-linked multimer, and the larger complex contains CLV3, the KAPP phosphatase, and a Rho-related GTPase, both possible downstream effectors. CLV1 and CLV3 are required for formation of the large complex (Trotochaud et al. 1999, 2000). The precise role of CLV2 in this pathway is unclear, although the observations that the accumulation of CLV1 protein is severely reduced in clv2 mutants (Kayes and Clark 1998; Jeong et al. 1999), and that CLV3 binds to yeast cells expressing CLV1 and CLV2 (Trotochaud et al. 2000) suggest that CLV1 and CLV2 proteins act as a heterodimer receptor complex. Some of these predictions are supported by CLV3 overexpression studies (Brand et al. 2000).

Despite these significant insights into meristem function in Arabidopsis, little is known about whether the mechanisms are conserved in other species. In particular, fasciated mutants have not been characterized at a molecular level in other plants. Interspecific differences in SAM structure and function make it interesting to ask how well conserved are the genes that control meristem development in Arabidopsis. Developmental changes in meristem function may underlie the yield increases brought about during the domestication and breeding of crops, and so it would be particularly interesting to understand how these genes function in crop plants. Maize is a good model system for cereal crop genetics and development, because of its rich genetic heritage and wellcharacterized morphology (Poethig 1993).

The maize ear is a particularly interesting system, as its development involves several meristem identity de- cisions (for review, see McSteen et al. 2000). The ear inflorescence meristem forms several rows of secondary meristems called spikelet pair meristems in a regular polystichous phyllotaxy. These meristems branch to form a pair of spikelet meristems, which branch again, to generate a pair of floral meristems. In the ear, one of the flowers will abort, and the other, when pollinated, will generate a single seed. The cob structure of the maize ear is unique among the grasses (Kellogg and Birchler 1993), and is evolutionarily derived from the distichous inflorescence of teosinte (Beadle 1980; Doebley 1992). However, teosinte inflorescences produce only a single alternating row of seeds, whereas modern maize lines produce from 8 to 18 , and some varieties up to 36 rows of seeds (USDA, ARS, National Genetic Resources Program, Germplasm Resources Information Network; http://www.ars-grin.gov/cgi-bin/npgs//. The ability of the inflorescence meristem to initiate a larger number of the secondary meristems that generate seed rows appears to be a major factor in the development of maize as a crop plant, and it would therefore be interesting to understand the mechanisms that regulate this aspect of ear inflorescence meristem function.

Here we describe a novel mutant of maize, fasciated ear2 (fea2). fea2 plants develop larger meristems during inflorescence and floral shoot development, and ear inflorescence meristems show severe fasciation, suggesting that fea2 normally acts to limit the growth of these meristems. fea2 encodes an LRR protein that is targeted to the plasmamembrane, suggesting that it acts as a receptor. fea2 is most closely related to the CLV2 gene of Arabidopsis, suggesting that the CLAVATA pathway is functionally conserved in monocot species.

\section{Results}

\section{Phenotypic analysis of fea 2 mutants}

The original fea2 allele, fea2-0, arose in a nontargeted screen of Mutator transposon families. A single family segregated plants with abnormally flattened ears, and sib and out crosses together with subsequent introgressions indicated that the mutation segregated as a simple recessive trait. A similar mutation was previously identified and named fasciated ear (Hake and Veit 1988). The new mutation was not allelic to fasciated ear, and we therefore named it fasciated ear2 (fea2). We have introgressed $f e a 2$ into several genetic backgrounds, and it shows strong phenotypic expression in all of them; we will describe the phenotypes of $f e a 2$ in the $\mathrm{B} 73$ genetic background. Unlike some $\mathrm{Mu}$ induced alleles (Martienssen and Baron 1994), there was no effect of $M u$ activity on the expressivity of the fea2 phenotype (data not shown).

Maize plants generate two distinct inflorescence structures; the terminal tassel bears male flowers, whereas the lateral inflorescences, the ears, bear female flowers. The most obvious phenotype of fea2 plants was in the development of the ears, which at maturity were abnormally flattened and wider than normal, with irregular rows of seeds (Fig. 1). The seed rows were irregular even 


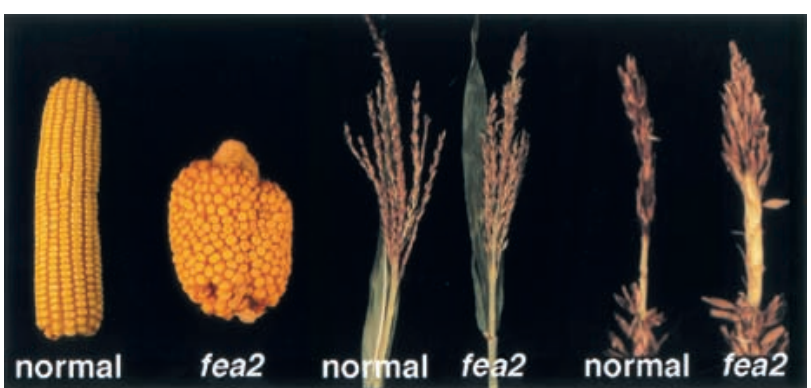

Figure 1. Mature ear and tassel phenotypes. From left, normal inbred B73 ear (female inflorescence), showing straight vertical rows of kernels. Next, an fea2 ear is shorter and wider than normal and is flattened, and the rows of kernels are irregular. The fea 2 ear contains more vertical rows of kernels. Next, normal and fea 2 tassel (male inflorescence) at this magnification appear similar. To the right, a higher magnification of part of the central spike of normal and fea2 tassels, from which some of the spikelets have been stripped in the central region. Note that the rachis or stem of the fea2 tassel spike is thicker than that of the normal tassel.

at the base of the ear, indicating that ear development was perturbed from an early stage. fea2 ears can have up to double the normal number of vertical rows of seeds (Table 1). However, as they are also shorter than normal the overall seed yield may not be higher. Compared to the ear, the tassel of fea2 plants was relatively normal, but when the spikelets were stripped off the central spike it was obvious that the rachis was slightly wider than normal, though it was not flattened or fasciated (Fig. 1). Consistent with the thicker rachis of fea2 tassels, the spikelet density in the tassel central spike was higher than normal (Table 1).

To determine when fea2 first affects meristem development, we measured shoot meristem size in cleared tissue slices. During vegetative seedling development, fea2 shoot meristems were almost indistinguishable from their normal sibs; meristem width was the same as normal and meristem height was slightly greater in fea2,

Table 1. Meristem size and inflorescence characteristics in normal and fea 2 ears

\begin{tabular}{|c|c|c|c|c|}
\hline & \multicolumn{2}{|c|}{ Vegetative SAM size ${ }^{\mathrm{a}}$} & \multirow{2}{*}{$\begin{array}{c}\text { Seed row no. } \\
\text { in ear }\end{array}$} & \multirow{2}{*}{$\begin{array}{l}\text { Spikelet density } \\
\text { in tassel }{ }^{\mathrm{c}}\end{array}$} \\
\hline & width/um & $\overline{\text { height } / \mu \mathrm{m}}$ & & \\
\hline B73 & $139(16)$ & 135 & 1 & 5.8 \\
\hline fea2 & $137(8)$ & $150(17)$ & $26-36$ & $6.8(0.8)$ \\
\hline
\end{tabular}

Numbers are mean values, with standard deviation in parentheses, except for row number, which shows the range of values. ${ }^{a}$ Measurements made on 14-day-old seedlings having $\sim 5$ visible leaves, $n=6-12$.

${ }^{\mathrm{b}}$ Range of number of vertical rows of seed in mid point of ear; $n=10$.

${ }^{\mathrm{c}}$ Number of spikelet pairs per $\mathrm{cm}$ on central spike of mature tassel, >300 spikelets were counted on 6-10 different tassels. Values for $f e a 2$ and $\mathrm{B} 73$ are significantly different by $t$-test $(P<0.05)$. though this may not be statistically significant (Table 1). In accord with these observations, fea2 plants showed no obvious abnormalities during vegetative development (data not shown). The ears are produced from lateral shoots, which first undergo a vegetative phase of development and produce several husk leaves before undergoing the transition to inflorescence development. During this transition, which under our growth conditions occurred between 25 and 30 days after planting, the size of the lateral shoot meristems increased slightly in normal B73 plants (Fig. 2). fea2 lateral ear shoot meristems were slightly wider and about twice as tall as normal prior to the inflorescence transition. However, around the time of this transition they enlarged profoundly, and almost doubled in both height and width in a few days (Fig. 2). Therefore, fea 2 acts to restrict lateral meristem size even before the inflorescence transition, but it is around the time of the transition that the fea2 mutant phenotype starts to be especially pronounced.

To visualize changes in inflorescence morphology, we observed immature ears during development using a scanning electron microscope. When fea2 ears were only 1-2 $\mathrm{mm}$ in length, the inflorescence meristem was obviously fasciated (Fig. 3C). Sections through ears at this stage hybridized in situ with knotted1 (kn1), a shoot meristem marker gene, showed that the whole of the fasci-

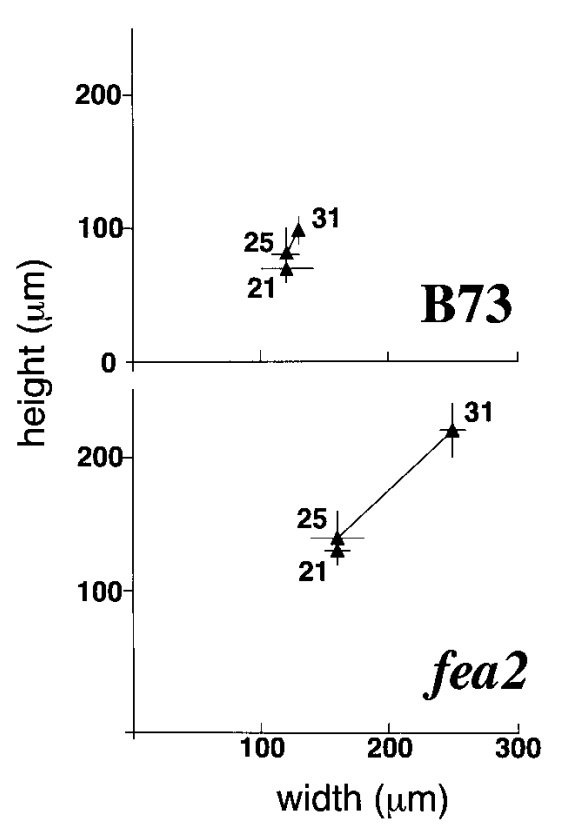

Figure 2. Meristem sizes in normal and fea2 lateral ear shoots. fea2 meristems proliferate significantly at the time of the inflorescence transition. The graph shows changes in the mean lateral shoot meristem width and height, measured immediately distal to the most recently initiated primordium, at 21, 25, and $31 \mathrm{~d}$ after planting. Measurements were taken from the uppermost lateral ear shoot from each plant; for each sample, $n=3-6$. Vertical and horizontal lines show standard deviation in height and width measurements, respectively. Note that the transition from vegetative to inflorescence development occurred between 25 and $31 \mathrm{~d}$ in these samples. 


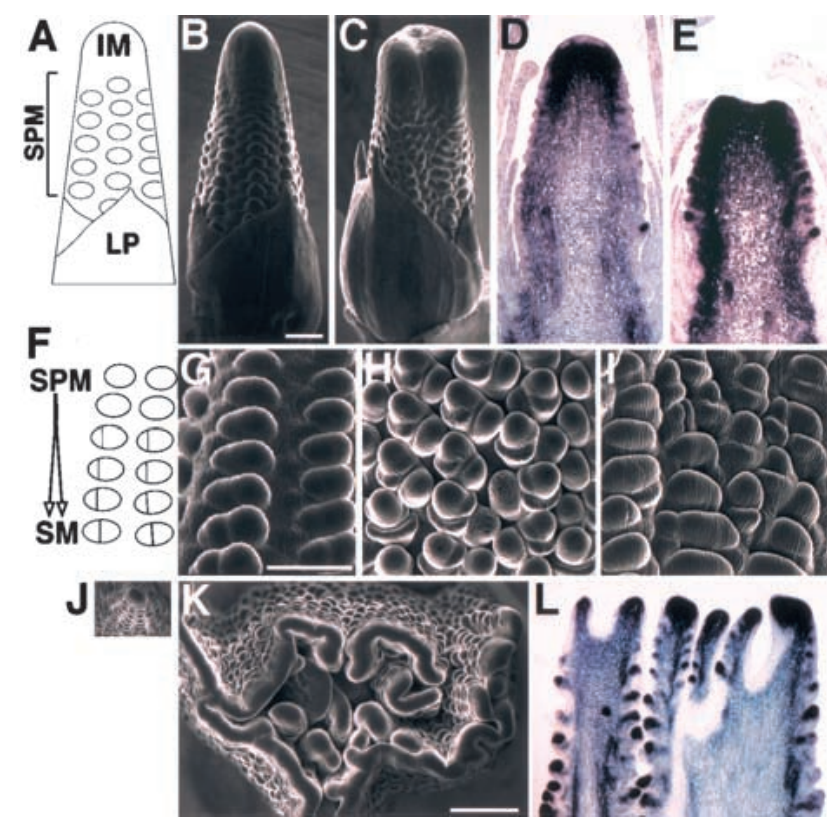

Figure 3. Morphogenesis and gene expression in normal and fea2 ears. (A) Schematic of an ear primordium showing inflorescence meristem (IM), spikelet pair meristems (SPM), and some of the surrounding husk leaf primordia (LP). (B) A normal, B73 inbred ear primordium. Bar, $250 \mu \mathrm{m} .(C)$ An fea2 ear primordium at a similar developmental stage. The tip of this ear primordium is flattened and a furrow is starting to form, and the rows of SPMs are irregular. $(D, E)$ Sections through similar stage of normal and fea2 ear primordia, respectively, probed in situ for kn1 mRNA. Both samples show strong staining at the tip of the ear shoot and sporadic staining on the sides when the section passes through an SPM. As ear development progresses, SPMs on the flank of the ear shoot branch to generate a pair of spikelet meristems (SMs), shown schematically in $(F)$. In normal ears $(G)$, this occurs as a gradual progression and generates pairs of spikelets that remain aligned in vertical rows. Bar, $250 \mu \mathrm{m}$. In fea2 ears, the plane of SPM branching and extent of branching is irregular $H, I$. In $H$, some SPMs appear to branch more than once, whereas in $(I)$, branching appears to be delayed, and wide, flattened SPMs are visible. At a later stage of development $(J-L)$, when the ear primordia are around $1 \mathrm{~cm}$ long, the fea 2 ear inflorescence phenotype is much more severe. SEM views looking down on the inflorescence meristem of a normal ear $(J)$ and $f e a 2$ ear $(K)$ are shown at the same magnification. Bar in $K, 1000 \mu \mathrm{m}$. In $L$, a section through an fea2 ear at a similar stage to the one shown in $K$, probed in situ for kn1, shows strong kn1 expression at the tips of each branch.

ated apical region expressed $k n 1$ strongly, indicating that it had normal shoot meristem identity.

We also observed abnormal development of the other meristem types on fea2 ears. The inflorescence meristem normally initiates spikelet pair meristems (SPMs) in a regular phyllotaxy, and the SPMs later branch to generate a pair of spikelet meristems (SMs) that are aligned in adjacent vertical rows (Fig. 3F,G). In fea2 ears, both the timing and orientation of SPM branching was disrupted, giving rise to irregular clusters of SMs as well as enlarged and flattened SPMs (Fig. 3H,I). As development proceeded, the fasciation became progressively more severe, and the apical region of fea2 ears enlarged to be more than 20 times wider than normal when the ears were 1-2 cm in length (Fig. 3, normal ear, J, shown at same magnification as fea2 ear, $\mathrm{K})$. The fea2 inflorescence meristem spread out into a ring and also split to generate many smaller inflorescence-like structures which also expressed kn1 strongly at their tips, suggesting that they retained shoot meristem identity (Fig. 3L). Consistent with the relatively mild phenotypes in the tassel, the tassel inflorescence meristems did not massively overproliferate, and were only mildly enlarged or fasciated (not shown).

Later in inflorescence development, each spikelet meristem branches to form a pair of floral meristems. In the ear, one of the floral meristems aborts, so only a single flower develops in each spikelet. On normal ears, the spikelets are paired (Fig. 4A,D); in fea2 ears, spikelets were occasionally in clusters of three (Fig. 4B), presumably as a consequence of the abnormal enlargement and branching of the SPMs observed at an earlier stage of development. Flower development was also abnormal in fea2 ears. Usually the floral meristem terminates with the production of the gynoecium, which contains three carpels, two of which grow out and fuse to form the forked silk (Fig. 4D). In fea2 ears, the gynoecium was often enlarged, and around $46 \%$ of the flowers $(n=100)$ produced extra carpel-like structures that were often fused (Fig. 4E).

fea2 mutants also developed abnormal spikelets and flowers in the tassel. One of the spikelets in the spikelet pair is supported on an extended internode called a pedicel (arrowed in Fig. 4F). fea2 spikelet pairs had consistently longer pedicels (Fig. $4 \mathrm{H}$ ); the mean pedicel length in fea2 spikelet pairs was $6.9 \pm 1.7 \mathrm{~mm}$, compared to normal pedicels, which were $5.1 \pm 1.4 \mathrm{~mm}(n=50)$. In addition, fea2 flowers had an abnormal numbers of stamens; male spikelets normally contain two flowers, each of which have three stamens (Fig. 4G). fea2 flowers had irregular numbers of stamens in $48 \%$ of their flowers $(n=50)$; the majority of abnormal flowers contained four stamens (Fig. 4I, arrowed).

To summarize, fea2 plants were defective in the regulation of meristem size in lateral branch and inflorescence phases, and the phenotype was most striking in the female inflorescence meristem. fea2 flowers produced extra carpel-like structures in the ear and extra stamens in the tassel. Therefore, in the normal inflorescence shoot, fea2 acts to limit the growth of all meristem types.

\section{Isolation of the fea2 gene}

Southern analysis using probes specific for different classes of $\mathrm{Mu}$ transposons identified a $4 \mathrm{~kb} M u 8$ hybridizing SstI fragment that cosegregated with fea2-0 in $~ 80$ individuals and was not present in sibling families that did not carry the fea2 mutation (data not shown). We used introgressed families that were selected for loss of $\mathrm{Mu}$ activity and contained many fewer $\mathrm{Mu}$ hybridizing bands to identify a larger cosegregating fragment, a $16 \mathrm{~kb}$ 

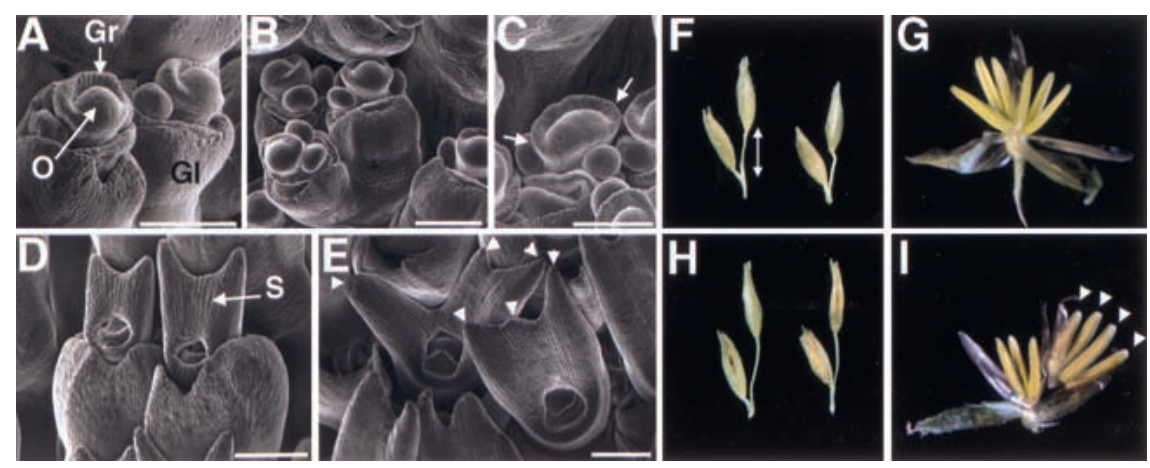

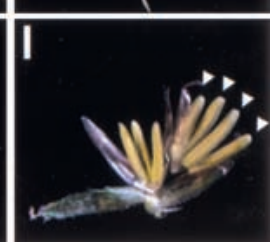

Figure 4. Abnormal spikelet and floral development in fea2 ears. Normal ears have spikelets arranged in pairs, each subtended by a leaf-like organ, the glume (Gl) $(A, D)$, and in each spikelet a single flower develops. The ovule primordium $(\mathrm{O})$ and gynoecial ridge (Gr), formed by the fusion of two carpel primordia, are visible in $A$. In $D$, at a later stage of development, the gynoecial ridge of each flower has grown out to form the forked silk primordium $(\mathrm{S})$, which is starting to cover the ovule primordium. fea2 ear spikelets and flowers are shown in $B, C$, and $E$. An abnormal clustering of three spikelets is seen in $B$. In $C$, the ovule primordium is enlarged and surrounded by a wider gynoecial ridge (arrowed). Two flowers with irregular numbers of carpels (arrowed) contributing to the silks are shown in $E$. Bar in each panel, $250 \mu \mathrm{m}$. $f e a 2 \mathrm{plants}$ also show defects in spikelet and flower development in the tassel. Normal male spikelets are arranged in pairs, and one is supported on an extended internode called a pedicel (arrow, $F)$. The pedicels in $f e a 2(H)$ are longer than normal; representative spikelets from the base (left) and middle region (right) of the tassel central spike are shown. In the tassels, spikelets normally contain two flowers, each with three anthers $(G)$; in the fea2 spikelet $(I)$, one of the flowers frequently contains four anthers (arrowed).

BamHI fragment that encompassed the $4 \mathrm{~kb}$ SstI fragment. Size-fractionated BamHI-digested genomic DNA from fea2-0 plants was cloned into a lambda phage library, and the library was probed with a Mus probe. Four positive clones were purified and restriction mapped, and subclones were isolated for analysis. One subclone, corresponding to the $550 \mathrm{bp}$ to the right side of the $\mathrm{Mu} 8$ element, identified a polymorphism between fea2-0 individuals and normal sibs (Fig. 5A). In SstI-digested fea2-0 genomic DNA, the 550-bp probe detected a single band of $4 \mathrm{~kb}$, as expected, and a smaller band of around $2.5 \mathrm{~kb}$ in normal sibs; the size difference corresponds to the size of the $M u 8$ transposon.

To determine whether the cloned fragment corresponded to fea2, we isolated a new fea2 allele by directed $\mathrm{Mu}$ transposon tagging. fea2-0 homozygotes were crossed onto $\mathrm{Mu}$ active plants, and $30,000 \mathrm{~F}_{1}$ seeds were planted in the 1999 summer field. Ears were screened at the time of pollen shed for fasciation. A single plant with severely fasciated ears was found in family 846 . This plant was out-crossed to fea2-0 and to normal testers, and analysis of $\mathrm{F}_{1}$ and $\mathrm{F}_{2}$ generations confirmed that the new allele, designated fea2-846, was allelic to fea2-0 and when homozygous had a phenotype indistinguishable from that of fea2-0 (data not shown). Southern analysis using the 550-bp flanking probe identified a novel polymorphism of $3 \mathrm{~kb}$ in size associated with this allele (Fig. $5 \mathrm{~A})$, confirming that we had correctly isolated the fea2 gene. Sequencing of this allele revealed that it was caused by the insertion of a $\mathrm{Mu} 7$ transposable element $\sim 300$ bp downstream of the position of the Mu8 insertion in fea2-0 (Fig. 5C). We mapped fea2 using recombinant inbred lines (Burr et al. 1988) to chromosome 4, bin 05, between markers uaz265c and npi284.

\section{fea2 is expressed widely in the shoot}

To identify an fea2 transcript, we probed RNA gel blots with the 550 -bp probe. A single transcript of $\sim 2.5 \mathrm{~kb}$ was detected in total RNA isolated from ear primordia, vegetative apex, and young leaf tissues, consisting of primordia still wrapped up in the whorl (Fig. 6). A very weak signal was detected in expanded leaf tissues, and no transcript was detected in root tissues. fea2 transcript was not found in extracts from fea2-0 mutant ear primordia, and a control probing with kn1 confirmed the integrity of these RNA extracts. Two ESTs for fea2 were recently sequenced from a 1-3 $\mathrm{mm}$ tassel cDNA library (http://gremlin3.zool.iastate.edu/zmdb/EST/). Therefore, fea2 is expressed in immature ear, tassel, vegetative apex, and young leaf tissues, and the transcript is not detected in fea2 ears. Despite several attempts using probes from different regions of the cDNA, we have been unable to detect a specific signal for fea2 by in situ hybridization, and conclude that the transcript is likely expressed widely rather than being concentrated in a specific domain or region of the apical region.

The lack of fea2 transcript in fea2-0 ears, together with the position of the Mu8 element in the exon, led us to suspect that $f e a 2-0$ was a null allele. To test this hypothesis genetically, we made plants hemizygous for fea2-0 using the TB 4Lc translocation stock (Birchler 1993). These plants developed ears with a fasciated phenotype similar to fea2-0 homozygotes (data not shown). Although this analysis was performed in a mixed genetic background, our observations suggest that the fea2-0 allele behaves genetically as a null (Muller 1932).

\section{fea2 encodes a predicted leucine-rich repeat receptor}

To identify the complete fea2 transcript, we used a combination of 5' and 3' RACE PCR (Frohman et al. 1988), using primers designed against the 550-bp clone to amplify cDNA prepared from 5-10 $\mathrm{mm}$ ear primordia. The products were subcloned and sequenced, and the sequences assembled and translated in silico. The $3^{\prime}$ RACE product contained 421 bp downstream of the first inframe stop codon in the major open reading frame. The 
Taguchi-Shiobara et al.
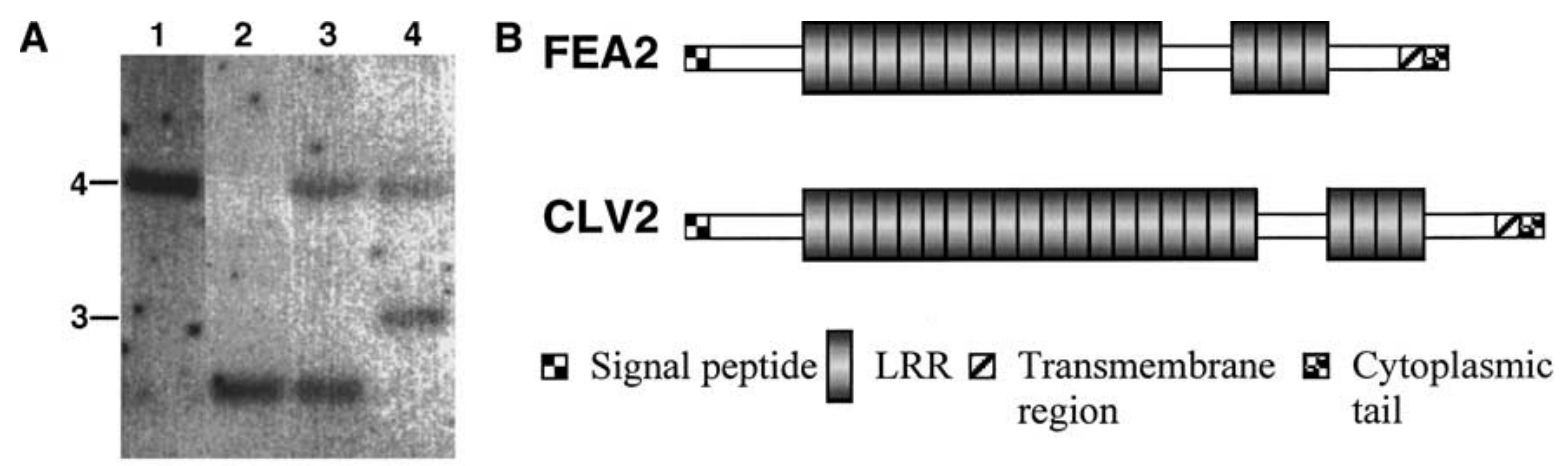

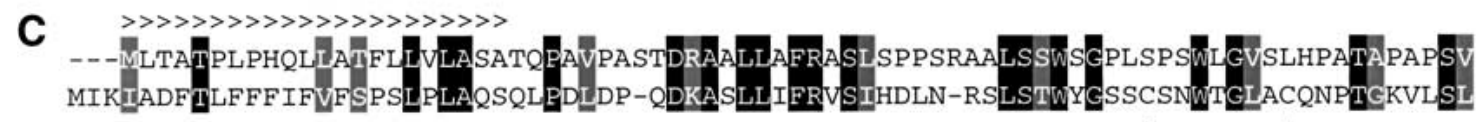
>>>>>>>>>>>>>>>>>>>>>>><smiles>O=S(=O)(O[Na])O[Na]</smiles>
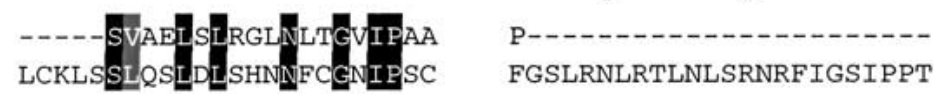

FMSLKELGEVVLSENRNLGGVVPHWF

GDFSMNLERVDLSFCSFVGELPES

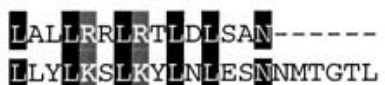

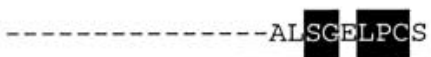
fEa 2-O
LPR--SLLALDLSRNALSGAVPTC
YASRPSLSVLNLAENSLVGGLPSC

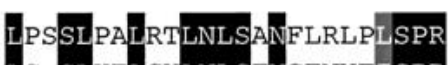
RDFQQPLVVLNLASNRFSGTLPCF

LSFPARLAALDLSRNAISGAVPPRIVA DPDNSALLLLDLSHNRFSGEIPAG LVESEKLVMLDLSHNGFSGRLPSRISE TTEKLGLVLLDLSHNSESGDIPLR

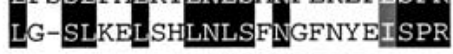
fea2-846

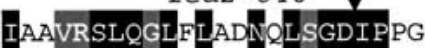

ITELKSLQALRLSHNLLTGDIPAR

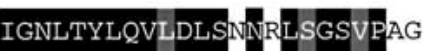
IGNLTYLOVIDLSHNSLTGSIPLN

TTDKLGLVLLDLSHNSESGDIPLR

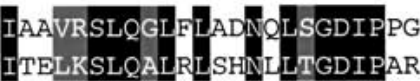

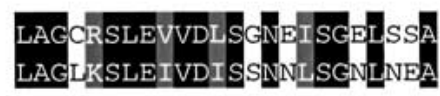
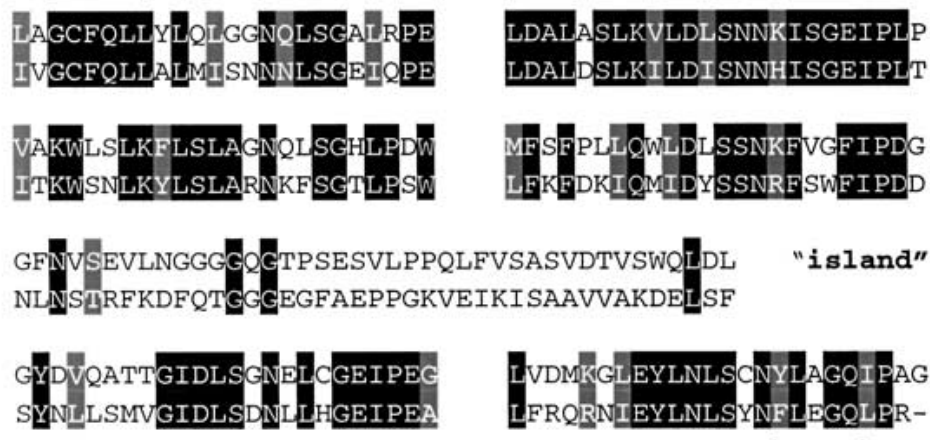

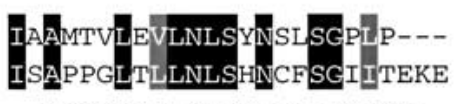
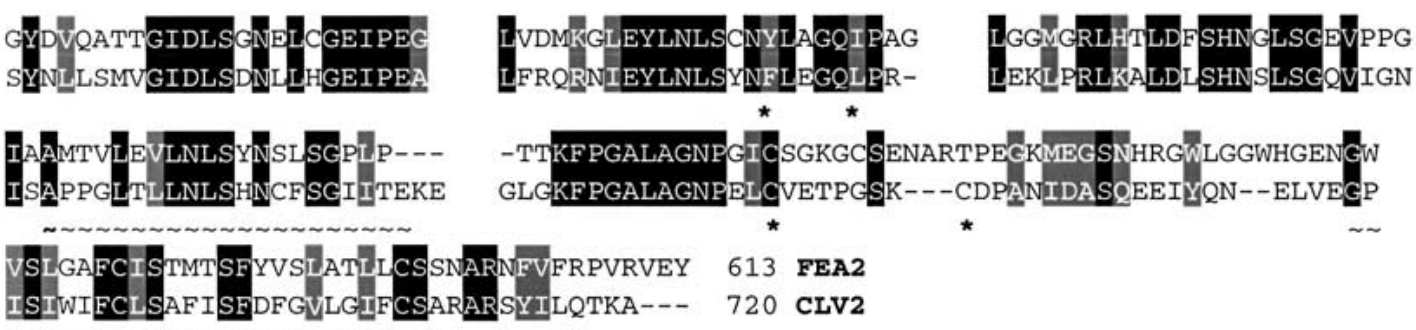

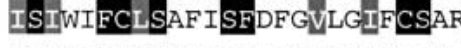

Figure 5. Molecular characterization of fea2. (A) Southern blot of SstI-digested genomic DNA from (1) fea2-0 homozygous mutant, (2) normal sib, (3) fea2-0 heterozygote, and (4) fea2-0/fea2-846 heterozygote. Note the novel $3 \mathrm{~kb}$ polymorphism in this plant associated with the fea2-846 mutation. The probe was the 550-bp fragment downstream of the Mu8 element in fea2-0. Values on the left side represent size in $\mathrm{kb} .(B)$ Schematic of predicted domains in FEA2 and CLV2 proteins. (C) CLUSTALW (http://dot.imgen.bcm.tmc.edu:9331/multialign/ Help/clustalw.html) alignment of FEA2 (from B73 inbred line; top line) and CLV2 (below, Genbank accession no. AAF02655). Identical residues are outlined in black, similar in gray; dashes represent gaps introduced to optimize the alignment, and "empty" gaps are introduced to separate each LRR motif, according to Thomas et al. (1997). Arrows indicate positions of the Mu transposon insertions in the two fea2 mutant alleles. Predictions of transmembrane and signal sequences are by SMART (http://smart.embl-heidelberg.de/) for FEA2 and from Jeong et al. (1999) for CLV2. These features are labeled above and below the respective sequences. (>>>) Signal peptide; ( ) transmembrane domain; $\left(^{\star *}\right)$ cysteine pair. 


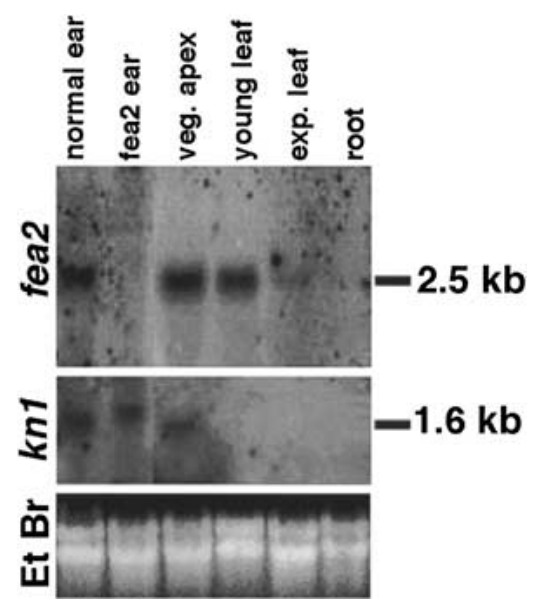

Figure 6. fea2 expression analysis. Total RNA, $10 \mu \mathrm{g} / \mathrm{lane}$ from normal ear primordia, fea2 ear primordia (5-15 mm long), vegetative seedling apex, young, unexpanded leaf, expanded leaf, and root tissues. fea 2 is expressed in normal ear primordia, vegetative apex, and young leaf tissue. Control probing with kn1 shows a signal in normal ear, fea2 ear, and vegetative apex, but not in leaf or root, as expected. Lower panel is the RNA gel stained with ethidium bromide and photographed on a UV light box, showing equal loading of RNA in all lanes.

longest 5' RACE product contained $43 \mathrm{bp}$ upstream of the first in frame ATG (data not shown). Comparison of the transcript sequence with that of the genomic DNA from the $\mathrm{Mu}$ flanking clone indicated that the predicted fea2 coding sequence is encoded by a single large exon.

A BLASTP search using the predicted translation of fea2 indicated similarity to a large number of plant receptor LRR proteins, with identity in the range of 30$34 \%$; however, the similarity was restricted to the LRR regions (data not shown). Only a single protein, CLV2, had significantly greater similarity to FEA2 that also included the non-LRR regions $(44 \%$ amino acid identity over most of the sequence, $58 \%$ similarity, Fig. 5C). Protein targeting and motif searching using SMART (http:// smart.embl-heidelberg.de// analysis predicted that FEA2 contains a signal peptide, a block of LRRs interrupted by a 40 amino acid island region, a transmembrane region and a 15 amino acid cytoplasmic tail (Fig. 5B). This domain structure is conserved in CLV2, except that CLV2 is predicted to have four more LRR repeats in the amino terminal cluster (Fig. 5B). A CLUSTALW alignment of FEA2 and CLV2 reveals that similarity is spread over the whole of the polypeptide sequence, although it is enhanced in the LRRs (Fig. 5C). For clarity, we introduced spaces in the alignments between each predicted LRR repeat, and it was clear that significant blocks of identity and similarity in the LRRs overlapped with the predicted solvent exposed residues thought to be involved in protein-ligand interaction (Kobe and Deisenhofer 1995; Thomas et al. 1997). In summary, FEA2 is closely related to the Arabidopsis CLV2 protein, and is predicted to contain extracytoplasmic LRRs, a transmembrane domain, and a short cytoplasmic tail.

\section{FEA2-GFP localizes to the plasma membrane}

To test the predicted membrane localization of FEA2, we made a translational fusion with a plant-optimized green fluorescent protein (GFP) (mGFP6, gift from Jim Haseloff) to the C terminus of FEA2, with a 10-alanine spacer to improve stability and folding (Doyle and Botstein 1996). The $\mathrm{C}$ terminus of FEA2 was chosen because if the $\mathrm{N}$ terminus was extracellular, the low $\mathrm{pH}$ of the cell wall might inhibit GFP fluorescence (Scott et al. 1999). The FEA2-GFP fusion was driven by the $35 \mathrm{~S}$ promoter in pRTL2 (Restrepo et al. 1990), and introduced into onion and Arabidopsis leaf epidermis by microprojectile bombardment.

Fluorescence from the FEA2-GFP fusion was observed using a confocal microscope, and was detected in a thin line at the cell periphery, consistent with plasma membrane localization (Fig. 7E-H) and similar to previous observations of GFP localization to the plasma membrane (Friedrichsen et al. 2000). The expression of free GFP also appeared at low magnification to be peripheral (Fig. 7A,D), due to the absence of GFP from the vacuole,
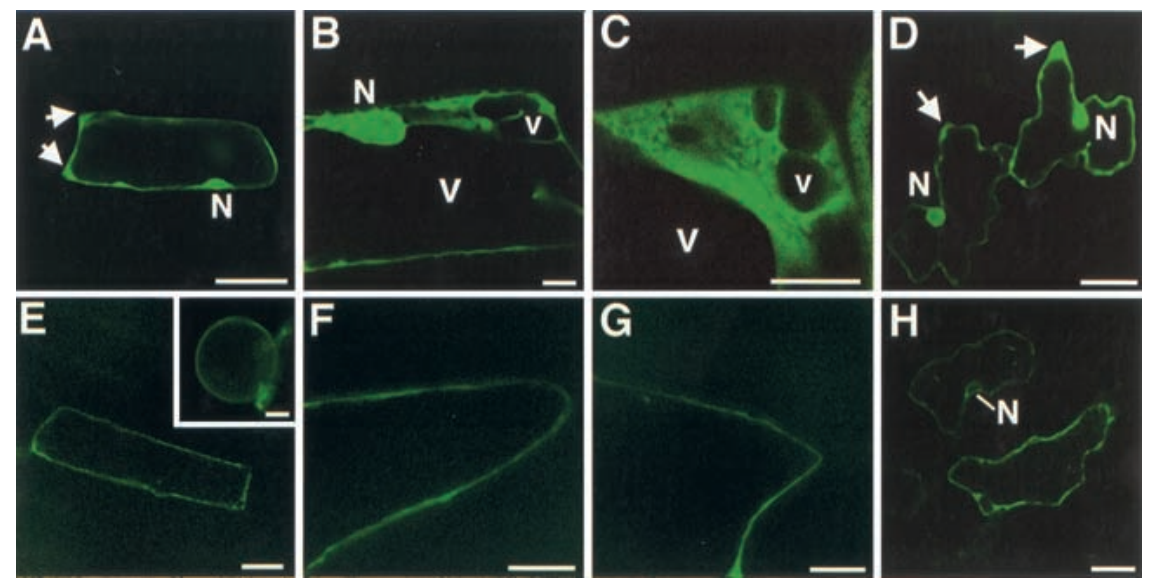

Figure 7. Subcellular localization of an FEA2-GFP fusion protein. Confocal microscopy images of cells expressing free GFP $(A-$ $D$ ) or the FEA2-GFP fusion $(E-H) . A-C$ and $E-G$ are images of onion scale epidermal cells. $D$ and $H$ are Arabidopsis leaf epidermal cells. In $A-D$, fluorescence is observed in cytoplasmic (arrowed) and nuclear (N) compartments, that are more easily visible at higher magnification in $B$ and $C$. Most of the central region of each cell is occupied by the vacuoles (V), which do not accumulate the GFP. In $E-H$, FEA2-GFP fluorescence is visible in a narrow line in the position of the plasmamembrane, as well as in a perinuclear line in onion ( $E$, inset) and Arabidopsis (N, panel $H$ ). In $A, E$, bar, $100 \mu \mathrm{m}(10 \mu \mathrm{m}$ in inset for panel $E)$. In $B-D, F-H$, bar, $25 \mu \mathrm{m}$. 
but at higher magnification the localization of free GFP throughout the cytoplasm and nucleoplasm was obvious (Fig. 7B,C). FEA2-GFP was also localized in a fine perinuclear line, possibly corresponding to the nuclear membrane (Fig. 7E inset, H). We also observed weak FEA2GFP fluorescence in the cytoplasm in a reticulate pattern, similar to the pattern observed when cells express an endoplasmic reticulum (ER)-localized GFP (data not shown; Haseloff et al. 1997). We conclude that FEA2GFP localizes in a pattern consistent with its targeting via the ER to the plasma membrane as well as to the nuclear membrane.

In conclusion, fea2 mutants have massive overproliferation of the ear inflorescence meristem, and more modest effects on spikelet and floral meristems, floral organ number, and pedicel length. fea2 encodes an LRR receptor-like protein that is expressed widely in immature shoot apical tissues and is a putative ortholog of CLV2 from Arabidopsis. FEA2-GFP localizes to the plasma membrane, consistent with its proposed role as a receptor-like protein and suggesting that it interacts with an extracellular ligand to control stem cell proliferation in shoot meristems.

\section{Discussion}

fea2 is a novel mutant of maize that develops enlarged inflorescence and floral meristems. In each, the effect is qualitatively similar, therefore fea2 normally functions in these meristems to restrict growth. However, fea2 phenotypes range from a modest increase in organ number in ear spikelet pairs and in both male and female flowers, to a massive overproliferation of the ear inflorescence meristem. Furthermore, it is surprising that the tassel inflorescence meristem, which in early development is very similar to that of the ear (McSteen et al. 2000), is only mildly affected by fea2 mutations, and does not develop strong fasciation. This difference could be explained by a redundant factor that can partially complement for fea2 function in the tassel. Although fea2 appears to be a single-copy gene in low stringency DNA blot hybridizations (data not shown), it is likely that there are multiple LRR receptor-like proteins, and cross talk between different LRR receptor-like or receptor proteins could account for genetic redundancy. Indeed, 30 CLV2-related LRR receptor-like proteins were found in the Arabidopsis genome sequence (Kaul et al. 2000). That the ear inflorescence meristem is more sensitive to loss of fea2 function may be due to selection on the ear to form an enlarged structure, which can accommodate multiple rows of seed (Doebley 1992). The ear inflorescence apex may therefore have somewhat more relaxed constraints on meristem proliferation. This hypothesis is based on an assumption that ear inflorescence meristem size increased to produce more rows of seeds, an idea that is supported by biophysical models of phyllotaxy as well as by studies on the abphyl1 mutation of maize that controls vegetative phyllotaxy (Green 1999; Jackson and Hake 1999). The difference between ear and tassel phenotypes might also be explained by the finding that the first products of the tassel inflorescence me- ristem are long branches that are initiated at about the same developmental stage as the inflorescence meristem starts to enlarge massively in fea2 ears. Perhaps the generation of these long branch primordia in the fea 2 tassel depletes cells or growth potential from the inflorescence meristem at a critical stage when it would otherwise fasciate.

fea2 encodes an LRR receptor-like protein that is most similar to CLV2 from Arabidopsis. In fact, CLV2 is the only protein encoded in the Arabidopsis genome that has significant similarity to the non-LRR regions of FEA2, suggesting that these genes are orthologous. These findings prompt the question of how well the CLV pathway is conserved in maize. Biochemical and overexpression studies suggest that in Arabidopsis, CLV1 and CLV2 heterodimerize to form a receptor for the secreted CLV3 signaling protein (Brand et al. 2000; Trotochaud et al. 2000), though the involvement of CLV2 is not biochemically proven. If the CLV pathway is conserved, are the specificities of the hypothetical receptor-ligand and receptor-heterodimer interactions conserved? Some insights into these questions come from the comparison of FEA2 and CLV2 sequences.

The majority of FEA2 is made up of LRRs, motifs of around 24-29 amino acids that are commonly used for protein-protein interactions (Kobe and Deisenhofer 1994, 1995). FEA2 contains 19 LRRs, with an "island" of about 40 amino acids between LRR repeats 15 and 16. A similar island region separates the $\mathrm{N}$-terminal LRRs from the four C-terminal LRRs in CLV2 (Jeong et al. 1999), the brassinosteroid receptor BRI1 (Li and Chory 1997), and the Cf resistance proteins of tomato (Thomas et al. 1997). Some insights into the control of receptorligand specificity have come from mutational and sequence analysis of these other LRR proteins. The LRR and transmembrane/juxtamembrane regions of BRI1 are sufficient for brassinosteroid perception, (He et al. 2000), and many bri1 mutations are clustered in the island region and the first LRR after the island, suggesting that these regions are important for ligand specificity (Li and Chory 1997; Friedrichsen et al. 2000). However, in Cf4 and $\mathrm{Cf} 9$, tomato LRR receptor-like proteins for different fungal elicitors, the island regions are identical, and in these receptors the ligand specificity is likely determined by the N-terminal LRRs (Thomas et al. 1997; Wulff et al. 2001). Other studies of resistance genes also indicate that the LRRs confer specificity in ligand interaction (for reviews, see Ronald 1998; Martin 1999; Ellis et al. 2000; Richter and Ronald 2000). Therefore, the LRRs, and in the case of BRI1, the island region also, appear to be important for ligand binding specificity. It is intriguing that the island regions of FEA2 and CLV2 are poorly conserved. Either this region is not important for specificity, or, if it is, FEA2 and CLV2 may bind to unrelated ligands. There are, however, significant blocks of identity and similarity between FEA2 and CLV2 in the LRRs, some of which coincide to the predicted solventexposed residues involved in LRR-ligand interactions (Kobe and Deisenhofer 1995; Thomas et al. 1997). Therefore, if the LRRs of these proteins do indeed confer speci- 
ficity, FEA2 and CLV2 could interact with related ligands.

Other features common in plant LRR proteins, including CLV2, include two pairs of cysteines spaced by six or seven amino acids that flank the LRRs, as well as a charged residue in the transmembrane region. These residues are proposed to mediate heterodimer formation (Jeong et al. 1999), and dimerization is a common feature for receptor activation, for example of receptor tyrosine kinases in animals (Ullrich and Schlessinger 1990; Schlessinger 2000). We do not know whether FEA2 forms a heterodimer in vivo, though it is likely because FEA2 has no obvious intracellular signaling domain. In contrast to CLV2, FEA2 has no charged residue in the transmembrane region, and lacks an $\mathrm{N}$-terminal cysteine pair, but does have a $\mathrm{C}$-terminal cysteine pair that is abnormally spaced by only four amino acids. Perhaps this is sufficient for dimerization of FEA2 with a hypothetical coreceptor. FEA2 also has several acidic residues in the extracellular region adjacent to the transmembrane domain that might also participate in a dimerization interface (Jeong et al. 1999).

In support of the hypothesis that monocots contain other components of the $C L V$ pathway, a rice gene related to $C L V 1, O S L R K 1$, was recently isolated (Kim et al. 2000). OsLRK1antisense plants developed an increased number of various floral organs; however, meristem size was not measured. In addition, there was no obvious phenotypic effect of OsLRK1antisense expression in the inflorescence meristem, suggesting that this gene may be functionally distinct from CLV1. However, it is unclear whether the OSLRK1antisense plants represent a full loss of function. The isolation of null alleles would address this question, and help determine the extent of conservation of CLV1 function in monocots.

fea2 is expressed widely in immature vegetative and inflorescence tissues, whereas it is down-regulated in expanded leaf tissue and is not expressed in the roots. The expression of fea2 during vegetative development appears to have no functional significance, as we have not observed any phenotype of fea2 mutants, for example in phyllotaxy or in leaf development. In addition to the inflorescence meristem phenotypes, fea2 plants have an increase in floral organ number that is presumably a consequence of the enlarged floral meristems. Male flowers have an increase in stamen number, and female flowers have an increase in carpel number. fea2 plants also have longer pedicels in the tassel spikelets, a phenotype that is reminiscent of the longer flower pedicel phenotype of clv2 mutants (Kayes and Clark 1998). We did not measure spikelet pedicels in the ear because they are highly reduced. Although the pedicel phenotype has been interpreted as an organ development phenotype distinct from the meristem phenotypes of $c l v 2$, we prefer to interpret it as another class of meristem phenotype, because the pedicel is an internode, and internodes develop from meristematic cells marked by KNOX gene expression (Jackson et al. 1994). Mutations in the rice OSH15 KNOX gene, which is expressed in the intercalary meristem that forms the internode, are dwarf due to reduced internode elongation (Sato et al. 1999). Therefore, just as fea2/CLV and KNOX mutations have opposing phenotypes in the shoot apical meristem, they also have opposite effects on internode elongation.

FEA2 is predicted to be membrane localized, and visualization of FEA2-GFP is consistent with its targeting to the plasma membrane. We also observed fluorescence in the position of the nuclear membrane; the significance of this expression is unclear, though it was reproducible and occurred in cells that had only very weak FEA2-GFP fluorescence, so was not an artifact of very high overexpression. Whether the nuclear membrane localization is significant awaits independent confirmation, for example by immunolocalization. The apparent plasma membrane accumulation of FEA2-GFP supports the hypothesis that FEA2 acts as a receptor for an extracellular ligand. The subcellular localization of CLV2 has not been demonstrated, though according to its proposed function as a coreceptor with CLV1, it is also likely to be localized to the plasma membrane.

The fasciation phenotype of fea2 mutants in the ear inflorescence meristem is much stronger than that described for clv2 in Arabidopsis inflorescence meristems. By molecular and genetic criteria, fea2-0 is likely a null allele. Similarly, the strong clv2-1 allele is likely a null as it has a stop codon at amino acid 33 (Jeong et al. 1999). It appears that despite the segmental allotetraploid nature of the maize genome (Gaut and Doebley 1997), there is less functional redundancy for fea2 in maize than for CLV2 in Arabidopsis. Alternatively, unrelated genes or pathways may have been recruited to perform CLV2- related functions specifically in Arabidopsis. As already discussed, the ear inflorescence meristem may be sensitized to meristem enlargement due to prior selection for increased number of rows of seeds on the ear. During this selection, the teosinte inflorescence meristem, which initiates secondary meristems singly in a distichous phyllotaxy, was converted to the maize inflorescence meristem, which initiates multiple rows in a polystichous phyllotaxy (Beadle 1980; Doebley 1992). It is conceivable that the change in phyllotaxy during the selection for the maize ear was accompanied by an increase in inflorescence meristem size, possibly by modification of genetic pathways that regulate meristem size, such as the $C L V$ pathway. An intriguing result in line with this hypothesis is that fea2 maps to the location of a quantitative trait locus for seed row number, a measure of the number of vertical rows of seed on the ear (Veldboom and Lee 1994). Observing that fea2 ears have up to twice the normal number of rows of seed, and that row number or spikelet density variants are of importance in other cereals such as barley, wheat, and rice (Futsuhara et al. 1979), it is possible that genes such as fea2 could be manipulated to improve crop yields.

\section{Materials and methods}

Isolation of fea2

We initially identified a $4 \mathrm{~kb}$ SstI Mu 8 hybridizing fragment that cosegregated with the fea2-0 mutation, and through analysis of 
lines with reduced $M u$ copy number found a corresponding 16kb BamHI fragment. Genomic DNA from fea2 homozygous plants was digested with $\mathrm{BamHI}$ and size-fractionated on a $0.8 \%$ agarose gel. DNA from several agarose strips in the $15-17 \mathrm{~kb}$ size range was extracted. After identification of the Mus-containing fraction by Southern blotting, this DNA fraction was cloned into the $\lambda$ dash vector (Stratagene), and the phage library was probed with a Mus probe. Four positive clones were isolated and subclones were prepared for Southern blotting, sequencing and mapping; a 550-bp SstI subclone was found to detect a polymorphism between DNA from fea2-0 plants and normal sibs. To isolate the full-length coding sequence, cDNA was prepared from immature ear primordia of $\sim 5-10 \mathrm{~mm}$ length using a reverse transcriptase kit (GIBCO BRL). Nested primers made to the 550-bp subclone sequence were used for 3' RACE (Frohman et al. 1988) and amplified a product of $\sim 1 \mathrm{~kb}$ that was cloned and sequenced. For isolation of the $5^{\prime}$ end of the coding sequence, a similar strategy was used, using cDNA prepared by the Marathon system (Clontech). The position of $M u$ insertions in the two fea2 alleles was determined by sequencing of PCR products generated using a $\mathrm{Mu}$ end-specific primer and an fea2-specific primer. The fea 2 coding sequence was subsequently amplified by proofreading PCR (Extaq, Takara) from B73 genomic DNA and sequenced; this is the sequence shown in Figure 5. The sequence has been submitted to GenBank, accession no. AY055124.

\section{RNA gel blot analysis}

Maize tissues were ground to a fine powder in liquid nitrogen and RNA was isolated using the Trizol procedure, according to the manufacturer's instructions (GIBCO BRL). RNA concentrations were determined using a spectrophotometer, and equal loading was verified by ethidium bromide staining of the gel after electrophoresis. RNA was denatured and separated by electrophoresis according to the method of Smith et al. (1992). The RNA was transferred to a Hybond-N membrane (Amersham Pharmacia Biotech), and hybridization of ${ }^{32} \mathrm{P}$-labeled probes was as described (Smith et al. 1992) at $42^{\circ} \mathrm{C}$ overnight. Blots were washed in $0.1 \times \mathrm{SSC}, 0.1 \%$ SDS at $65^{\circ} \mathrm{C}$ for two times one $\mathrm{h}$ and exposed to a PhosphorImager screen (Fuji). For fea2, the 550-bp subclone downstream of the $M u 8$ insertion site in fea2- 0 was used as a probe, and for kn1 we used the whole cDNA (Vollbrecht et al. 1991).

\section{Phenotypic analysis}

All measurements were made on fea2- 0 mutants introgressed four or more generations into the B73 inbred background. B73 normal plants or heterozygous sibs were used as the control. Meristem measurements were made on fixed and cleared specimens, as described (Jackson and Hake 1999), and were made by defining the shoot meristem as the area of tissue distal to the most recently initiated primordium. Scanning electron microscopy was performed on fresh tissue using an S-3500N SEM (Hitachi). Samples were dissected and mounted on a stub in silver paint, and all cut tissue surfaces were sealed with silver paint (Electron Microscopy Sciences). Stubs were cooled on ice for 5-30 min before being transferred to the microscope. Imaging was performed at high vacuum using $3-5 \mathrm{kV}$ accelerating voltage and a secondary electron detector. Images were collected electronically and transferred to Adobe Photoshop for generation of montages.

\section{In situ hybridization}

Maize ear primordia were dissected, vacuum infiltrated, and fixed in $4 \%$ formaldehyde, prepared fresh from paraformalde- hyde (Sigma) in phosphate-buffered saline at $4^{\circ} \mathrm{C}$ overnight. In situ hybridizations were performed as described (Jackson et al. 1994).

\section{FEA2-GFP imaging}

PCR was used to generate a BamHI restriction site to replace the stop codon of fea2 and allow its fusion in-frame to a fragment comprising a 10-alanine linker followed by mGFP6 in pRTL2 (Restrepo et al. 1990). A 1300-bp PCR fragment was generated using a proofreading polymerase (ExTaq, Takara), and the primers 1b550-T7b CTTGATCTCTCCCGCAACGCCAT CTCC and fea2-3'Bam CTAGGATCCGCATATTCAACCCT CACAGGCC, and this fragment was cloned and then ligated together with the $5^{\prime}$ RACE PCR clone of fea2 using a unique SbfI site in the coding sequence. At the $5^{\prime}$ end, a XhoI site introduced when cloning the 5' RACE product of fea2, $43 \mathrm{bp}$ upstream of the ATG, was used to complete the cloning. The resulting construct contained the FEA2-alanine linker-GFP fusion under the control of a double $35 \mathrm{~S}$ promoter. The part of the construct generated by the PCR was sequenced to check for possible amplification errors. Next, $0.5 \mu \mathrm{g}$ of plasmid DNA from this construct, or a similar construct, pZY212, for expression of free GFP, was precipitated onto $1.5 \mathrm{mg}$ of gold particles $(1 \mu \mathrm{m}$, Biorad) according to the manufacturer's guidelines. The gold particles were resuspended in ethanol and divided into three aliquots for bombardments. Slices of onion scale or intact Arabidopsis plants that were grown under short day conditions for 4-5 wk were bombarded using a PDS-1000 system using 900 or 450 psi pressure, respectively. Bombarded samples were kept in the incubator for $2 \mathrm{~d}$ before observation of fluorescence spots with a Leica MZ FLIII fluorescence dissecting microscope and a Zeiss LSM confocal microscope. Images were scanned using a $20 \times$ objective or a $63 \times$ water immersion objective.

\section{Acknowledgments}

We thank Dr. Paul Chomet for allowing us to screen Dekalb/ Monsanto's propriety Mu field. We also thank Jim Haseloff for generously providing the mGFP6 clone, Ben Burr for help with RI mapping, Peter Rogowsky for maize ear cDNA, Sarah Archer Evans for the FEA2-GFP construct, Greg Sabino for help with field work and molecular biology, and members of the Jackson lab and Erik Vollbrecht for comments and help with statistical analysis. A special thanks also to Tim Mulligan for providing outstanding field and greenhouse support. We acknowledge generous support from the USDA NRIGCP, award 1999-01793, NSF DBI-9970149, and CSHL Institutional Funds. F.T.S. was funded by a Japanese Science and Technology Agency (STA) fellowship.

The publication costs of this article were defrayed in part by payment of page charges. This article must therefore be hereby marked "advertisement" in accordance with 18 USC section 1734 solely to indicate this fact.

\section{References}

Barton, M.K. and Poethig, R.S. 1993. Formation of the shoot apical meristem in Arabidopsis thaliana-An analysis of development in the wild type and in the shoot meristemless mutant. Development 119: 823-831.

Beadle, G.W. 1980. The ancestry of corn. Sci. Am. 242: 112-119.

Birchler, J.A. 1993. Dosage analysis using B-A translocations. In The maize handbook. pp. 328-329. Springer Verlag, New York.

Bowman, J.L. and Eshed, I. 2000. Formation and maintenance of 
the shoot apical meristem. Trends Plant Sci. 5: 110-115.

Brand, U., Fletcher, J.C., Hobe, M., Meyerowitz, E.M., and Simon, R. 2000. Dependence of stem cell fate in Arabidopsis on a feedback loop regulated by CLV3 activity. Science 289: 617-619.

Burr, B., Burr, F.A., Thompson, K.H., Albertson, M.C., and Stuber, C.W. 1988. Gene mapping with recombinant inbreds in maize. Genetics 118: 519-526.

Clark, S.E., Running, M.P., and Meyerowitz, E.M. 1993. CLAVATA1, a regulator of meristem and flower development in Arabidopsis. Development 119: 397-418.

- 1995. CLAVATA3 is a specific regulator of shoot and floral meristem development affecting the same processes as CLAVATA1. Development 121: 2057-2067.

Clark, S.E., Jacobsen, S.E., Levin, J.Z., and Meyerowitz, E.M. 1996. The CLAVATA and SHOOT MERISTEMLESS loci competitively regulate meristem activity in Arabidopsis. Development 122: 1567-1575.

Clark, S.E., Williams, R.W., and Meyerowitz, E.M. 1997. The CLAVATAl gene encodes a putative receptor kinase that controls shoot and floral meristem size in Arabidopsis. Cell 89: $575-585$.

Doebley, J. 1992. Mapping the genes that made maize. Trends Genet. 8: 302-307.

Doyle, T. and Botstein, D. 1996. Movement of yeast cortical actin cytoskeleton visualized in vivo. Proc. Natl. Acad. Sci. 93: 386-391.

Ellis, J., Dodds, P., and Pryor, T. 2000. Structure, function and evolution of plant disease resistance genes. Curr. Opin. Plant Biol. 3: $278-284$.

Emerson, R.A. 1912. Inheritance of certain "abnormalities" in maize. Am. Breed. Assoc. Rept. 8: 385-399.

Endrizzi, K., Moussian, B., Haecker, A., Levin, J.Z., and Laux, T. 1996. The SHOOT MERISTEMLESS gene is required for maintenance of undifferentiated cells in Arabidopsis shoot and floral meristems and acts at a different regulatory level than the meristem genes WUSCHEL and ZWILLE. Plant $J$. 10: $101-113$.

Evans, M.M.S. and Barton, M.K. 1997. Genetics of angiosperm shoot apical meristem development. Ann. Rev. Plant Physiol. Plant Mol. Biol. 48: 673-701.

Fletcher, L.C., Brand, U., Running, M.P., Simon, R., and Meyerowitz, E.M. 1999. Signaling of cell fate decisions by CLAVATA3 in Arabidopsis shoot meristems. Science 283: 1911-1914.

Friedrichsen, D.M., Joazeiro, C.A.P., Li, J.M., Hunter, T., and Chory, J. 2000. Brassinosteroid-insensitive-1 is a ubiquitously expressed leucine-rich repeat receptor serine/threonine kinase. Plant Physiol. 123: 1247-1255.

Frohman, M.A., Dush, M.K., and Martin, G.R. 1988. Rapid production of full-length cDNAs from rare transcripts: Amplification using a single gene-specific oligonucleotide primer. Proc. Nat1. Acad. Sci. 85: 8998-9002.

Futsuhara, Y., Kondo, S., and Kitano, H. 1979. Genetical studies on dense and lax panicles in rice. Japan J. Breed 29: 239-247.

Gaut, B.S. and Doebley, J.F. 1997. DNA sequence evidence for the segmental allotetraploid origin of maize. Proc. Natl. Acad. Sci. 94: 6809-6814.

Green, P.B. 1999. Expression of pattern in plants: Combining molecular and calculus based biophysical paradigms. Am. J. Bot. 8: 1059-1076.

Hake, S. and Veit, B. 1988. New ear phenotype recovered in $\mathrm{Mu}$ field-"fascinated ear". Maize Genet. Coop. Newslett. 62: 2.

Haseloff, J., Siemering, K.R., Prasher, D.C., and Hodge, S. 1997. Removal of a cryptic intron and subcellular localization of green fluorescent protein are required to mark transgenic
Arabidopsis plants brightly. Proc. Natl. Acad. Sci. 94: 21222127.

He, Z.H., Wang, Z.Y., Li, J.M., Zhu, Q., Lamb, C., Ronald, P., and Chory, J. 2000. Perception of brassinosteroids by the extracellular domain of the receptor kinase BRI1. Science 288: $2360-2363$

Jackson, D. and Hake, S. 1999. Control of phyllotaxy in maize by the abphyl1 gene. Development 126: 315-323.

Jackson, D., Veit, B., and Hake, S. 1994. Expression of maize KNOTTED1 related homeobox genes in the shoot apical meristem predicts patterns of morphogenesis in the vegetative shoot. Development 120: 405-413.

Jeong, S., Trotochaud, A.E., and Clark, S.E. 1999. The Arabidopsis CLAVATA2 gene encodes a receptor-like protein required for the stability of the CLAVATA1 receptor-like kinase. Plant Cell 11: 1925-1933.

Kaul, S., Koo, H.L., Jenkins, J., Rizzo, M., Rooney, T., Tallon, L.J., Feldblyum, T., Nierman, W., Benito, M.I., Lin, X.Y., et al. 2000. Analysis of the genome sequence of the flowering plant Arabidopsis thaliana. Nature 408: 796-815.

Kaya, H., Shibahara, K., Taoka, K., Iwabuchi, M., Stillman, B., and Araki, T. 2001. FASCIATA genes for chromatin assembly factor-1 in Arabidopsis maintain the cellular organization of apical meristems. Cell 104: 131-142.

Kayes, J.M. and Clark, S.E. 1998. CLAVATA2, a regulator of meristem and organ development in Arabidopsis. Development 125: 3843-3851

Kellogg, E. and Birchler, J. 1993. Linking phylogeny and genetics: Zea mays as a tool for phylogenetic studies. Syst. Biol. 42: 435-439.

Kerstetter, R.A., Laudencia-Chingcuanco, D., Smith, L.G., and Hake, S. 1997. Loss of function mutations in the maize homeobox gene, knotted1, are defective in shoot meristem maintenance. Development 124: 3045-3054.

Kim, C.H., Jeong, D.H., and An, G.H. 2000. Molecular cloning and characterization of OsLRK1 encoding a putative receptor-like protein kinase from Oryza sativa. Plant Sci. 152: $17-26$.

Kobe, B. and Deisenhofer, J. 1994. The leucine-rich repeat-A versatile binding motif. Trends Biochem. Sci. 19: 415-421. - 1995. A structural basis of the interactions between leucine-rich repeats and protein ligands. Nature 374: 183-186.

Laufs, P., Dockx, J., Kronenberger, J., and Traas, J. 1998a. MGOUN1 and MGOUN2: Two genes required for primordium initiation at the shoot apical and floral meristems in Arabidopsis thaliana. Development 125: 1253-1260.

Laufs, P., Jonak, C., and Traas, J. 1998b. Cells and domains: Two views of the shoot meristem in Arabidopsis. Plant Physiol. Biochem. 36: 33-45.

Laux, T., Mayer, K.F.X., Berger, J., and Jurgens, G. 1996. The Wuschel gene is required for shoot and floral meristem integrity in Arabidopsis. Development 122: 87-96.

Leyser, H.M.O. and Furner, I.J. 1992. Characterisation of three shoot apical meristem mutants of Arabidopsis thaliana. Development 116: 397-403.

Li, J.M. and Chory, J. 1997. A putative leucine-rich repeat receptor kinase involved in brassinosteroid signal transduction. Cell 90: 929-938.

Long, J.A., Moan, E.I., Medford, J.I., and Barton, M.K. 1996. A member of the KNOTTED class of homeodomain proteins encoded by the SHOOTMERISTEMLESS gene of Arabidopsis. Nature 379: 66-69.

Luckwill, L.C. 1943. The evolution of the cultivated tomato. Jour. Royal Hort. Soc. 68: 19-25.

Martienssen, R. and Baron, A. 1994. Coordinate suppression of mutations caused by Robertson's Mutator transposons in 
maize. Genetics 136: 1157-1170.

Martin, G.B. 1999. Functional analysis of plant disease resistance genes and their downstream effectors. Curr. Opin. Plant Biol. 2: 273-279.

Mayer, K.F., Schoof, H., Haecker, A., Lenhard, M., Jurgens, G., and Laux, T. 1998. Role of WUSCHEL in regulating stem cell fate in the Arabidopsis shoot meristem. Cell 95: 805-815.

McSteen, I., Laudencia-Chingcuanco, I., and Colasanti, I. 2000. A floret by any other name: Control of meristem identity in maize. Trends Plant Sci. 5: 61-66.

Medford, J. 1992. Vegetative apical meristems. Plant Cell 4: 1029-1039.

Medford, J.I., Behringer, F.J., Callos, J.D., and Feldmann, K.A. 1992. Normal and abnormal development in the Arabidopsis vegetative shoot apex. Plant Cell 4: 631-643.

Meyerowitz, E.M. 1997. Genetic control of cell division patterns in developing plants. Cell 88: 299-308.

Muller, H.J. 1932. Further studies on the nature and causes of gene mutations. Proc. Int. Congr. Genet. 1: 213-255.

Poethig, R.S. 1993. The maize shoot. In The maize handbook. pp. 11-16. Springer Verlag, New York.

Restrepo, M.A., Freed, D.D., and Carrington, J.C. 1990. Nuclear transport of plant potyviral proteins. Plant Cell 2: 987-998.

Richter, T.E. and Ronald, P.C. 2000. The evolution of disease resistance genes. Plant Mol. Biol. 42: 195-204.

Ronald, P.C. 1998. Resistance gene evolution. Curr. Opin. Plant Biol. 1: 294-298.

Sato, Y., Sentoku, N., Miura, Y., Hirochika, H., Kitano, H., and Matsuoka, M. 1999. Loss-of-function mutations in the rice homeobox gene OSH15 affect the architecture of internodes resulting in dwarf plants. EMBO J. 18: 992-1002.

Schlessinger, J. 2000. Cell signaling by receptor tyrosine kinases. Cell 103: 211-225.

Scott, A., Wyatt, S., Tsou, P.L., Robertson, D., and Allen, N.S. 1999. Model system for plant cell biology: GFP imaging in living onion epidermal cells. Biotechniques 26: 1125-1128.

Smith, L.G., Greene, B., Veit, B., and Hake, S. 1992. A dominant mutation in the maize homeobox gene, Knotted-1, causes its ectopic expression in leaf cells with altered fates. Development 116: 21-30.

Sussex, I.M. 1952. Regeneration of the potato shoot apex. Nature 170: 755-757.

Thomas, C.M., Jones, D.A., Parniske, M., Harrison, K., BalintKurti, P.J., Hatzixanthis, K., and Jones, J.D. 1997. Characterization of the tomato Cf-4 gene for resistance to Cladosporium fulvum identifies sequences that determine recognitional specificity in Cf-4 and Cf-9. Plant Cell 9: 2209-2224.

Trotochaud, A.E., Hao, T., Wu, G., Yang, Z.B., and Clark, S.E. 1999. The CLAVATA1 receptor-like kinase requires CLAVATA3 for its assembly into a signaling complex that includes KAPP and a Rho-related protein. Plant Cell 11: 393-405.

Trotochaud, A.E., Jeong, S., and Clark, S.E. 2000. CLAVATA3, a multimeric ligand for the CLAVATA1 receptor-kinase. Science 289: 613-617.

Ullrich, A. and Schlessinger, J. 1990. Signal transduction by receptors with tyrosine kinase activity. Cell 61: 203-212.

Veldboom, L.R. and Lee, M. 1994. Molecular-marker-facilitated studies of morphological traits in maize. 2. Determination of QTLs for grain-yield and yield components. Theor. Appl. Genet. 89: 451-458.

Vollbrecht, E., Veit, B., Sinha, N., and Hake, S. 1991. The developmental gene Knotted-1 is a member of a maize homeobox gene family. Nature 350: 241-243.

Vollbrecht, E., Reiser, L., and Hake, S. 2000. Shoot meristem size is dependent on inbred background and presence of the maize homeobox gene, knotted1. Development 127: 31613172 .

Weigel, D. and Clark, S.E. 1996. Sizing up the floral meristem. Plant Physiol. 112: 5-10.

Wulff, B.B.H., Thomas, C.M., Smoker, M., Grant, M., and Jones, J.D.G. 2001. Domain swapping and gene shuffling identify sequences required for induction of an Avr-dependent hypersensitive response by the tomato Cf- 4 and Cf- 9 proteins. Plant Cell 13: 255-272.

Zielinski, Q. 1945. Fascination in horticultural plants with special reference to the tomato. Proc. Am. Hort. Sci. 46: 263 268. 


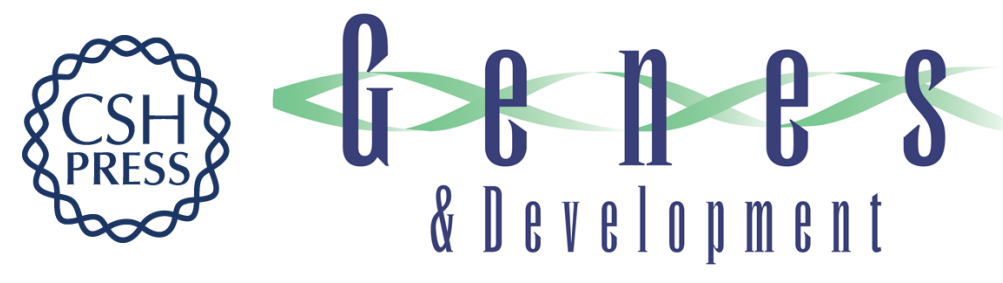

\section{The fasciated ear2 gene encodes a leucine-rich repeat receptor-like protein that regulates shoot meristem proliferation in maize}

Fumio Taguchi-Shiobara, Zhuang Yuan, Sarah Hake, et al.

Genes Dev. 2001, 15:

Access the most recent version at doi:10.1101/gad.208501

References This article cites 61 articles, 31 of which can be accessed free at:

http://genesdev.cshlp.org/content/15/20/2755.full.html\#ref-list-1

License

Email Alerting Receive free email alerts when new articles cite this article - sign up in the box at the top Service right corner of the article or click here.

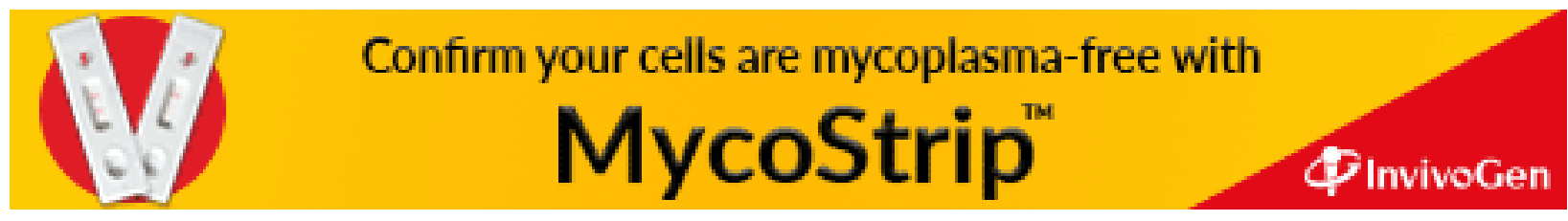

